\title{
Comparative Experimental Study of Friction Parameters in a Tribopair and a Force System
}

\author{
L. A. Sosnovskii ${ }^{a}$ *, V. V. Komissarov ${ }^{a}$, and S. S. Shcherbakov ${ }^{b}$ \\ ${ }^{a}$ Belarussian State University of Transport, ul. Kirova 34, Gomel, 246050 Belarus \\ ${ }^{b}$ Belarussian State University, pr. Nezavisimosti 4, Minsk, 220030 Belarus \\ *e-mail: komissarov@belsut.gomel.by \\ Received April 18, 2011
}

\begin{abstract}
The paper presents the results of experimental study of the effect of stresses resulting from off-contact load on variations in the friction torque and the coefficient of resistance to rolling in a force system compared to a similar tribopair. The results are compared with the theoretical data obtained on the basis of the deformation approach to the analysis of friction. It is shown that the calculation estimates agree well with the experimental results both qualitatively (the regularities) and quantitatively (the numerical values). The error of the determination of the coefficient of resistance to rolling does not exceed $7 \%$. The study results make it possible to formulate and solve the problem of the effective control over the friction force (coefficient) by varying cyclic (bending) stresses.
\end{abstract}

Keywords: force (tribo-fatigue) system, tribopair, friction, law of friction, coefficient of resistance to rolling, contact load, contact area.

DOI: $10.3103 / \mathrm{S} 1068366612030105$

\section{INTRODUCTION}

In tribology the friction force, which arises during the friction of macroscopic objects, is assumed to depend on only one force factor, namely, the normal contact load [1-3]. In force or tribo-fatigue systems, in which the stress-strain state is caused by the effect of both the contact and volume loads excited in the same zone, the stresses and strains resulting from an offcontact load form additional boundary conditions on the contact surface. This varies considerably the tribological characteristics. Theoretical studies [4-6] have shown that in a tribo-fatigue system the resulting rolling friction force (coefficient) in the tension zone declines compared to the pure rolling force (coefficient) under the simultaneous action of contact and off-contact loads and, conversely, this force increases in the compression zone.

The aim of the study is to study experimentally the effect of the stresses resulting from off-contact load on variations in the coefficient of resistance to rolling in a force system and a similar tribopair and to compare the data with the results of the theoretical solutions.

\section{PROBLEM FORMULATION}

The traditional approach to the determination of the friction coefficient is that the friction force and coefficient in the tribopair are assumed to depend only on the contact load $F_{N}$ (contact pressure $p$ ):

$$
f(p)=\frac{F_{S}}{F_{N}}=\frac{\tau_{W}}{p},
$$

where $F_{S}$ is the friction force, $\tau_{W}$ is the specific friction force, $F_{N}$ is the contact load, and $p$ is the contact pressure.

From the viewpoint of tribo-fatigue, the friction coefficient in force systems is determined as a function of the contact pressure $p$ and the cyclic stresses $\sigma$ resulting from the off-contact load:

$$
f(p, \sigma)=\frac{F_{S}(p, \sigma)}{F_{N}} .
$$

According to the data of [4-6], depending on the conditions of friction or testing it can be

$$
f(p, \sigma) \gtreqless f(p),
$$

i.e., the cyclic stresses can either increase or reduce the friction coefficient.

In this work, we carried out the systematic comparative analysis of relations (1)-(3) based on the experimental results; all tests were performed under rolling friction conditions so that $f(p)=f_{r}$ is the coefficient of resistance to rolling in the friction pair and $f(p, \sigma)=f_{\sigma}$ is the coefficient of resistance to rolling in the force system.

A modification of the roller/shaft force system (steel 18KhGT/steel 18KhGT) was tested (Fig. 1); the test method was published earlier [7]. 


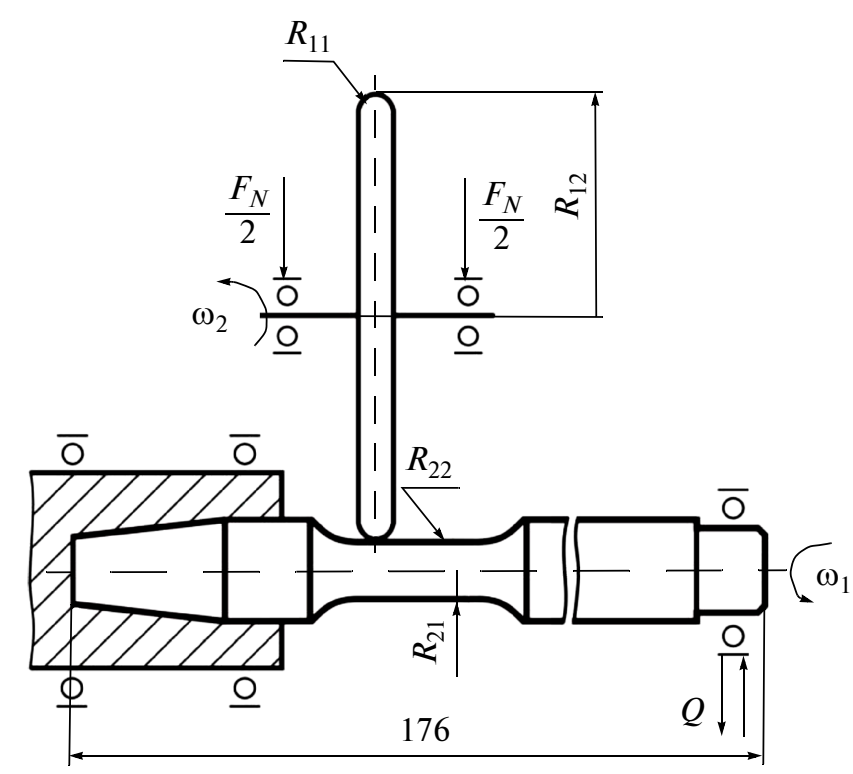

Fig. 1. Model for mechano-roling fatigue tests.

\section{RESULTS OF TESTING THE STEEL 18KhGT/STEEL 18KhGT FORCE SYSTEM}

This force system was tested using the developed method at three values of the contact stresses $\left(p_{0}=\right.$ $2000 \mathrm{MPa}, p_{0}=3200 \mathrm{MPa}$, and $\left.p_{0}=5600 \mathrm{MPa}\right)$, which correspond to the range of elastic and elastoplastic deformations (see the dependence of the maximum contact pressure $p_{0}$ on the approach of the axes $\delta_{c}$-insert in Fig. 2). The bending load $Q$ was assigned stepwise $5 \mathrm{~min}$ after the beginning of the tests. The initial bending load was $Q=160 \mathrm{~N}$ (the bending stresses were $\left.\sigma_{a}=160 \mathrm{MPa}\right)$. The increment of the bending stresses at each loading step was $\Delta \sigma_{i}=40 \mathrm{MPa}=$ const; the duration of the step was $n_{i}=30000$ cycles. The bending load was directed downwards to produce tensile stresses in the contact zone and upwards to produce compressive stresses (see Fig. 1). The degree of slippage was constant during the tests and amounted to $\lambda=3 \%$.

The test results are presented as the graphs of the dependence of the average coefficient of resistance to rolling $\overline{f_{\sigma}}$ (under various values of the contact stresses $p_{0}$ ) on the cycle stress amplitude $\sigma_{a}$ at the given loading step (Fig. 2). Sixty values of $f_{\sigma}$ obtained during the test at one loading step (10 $\mathrm{min})$ correspond to each point on the graph at $\sigma_{a}=$ const; this provides a sufficient accuracy of the results. The data presented in Fig. 2 allow us to draw the following conclusions.

(1) During the contact fatigue tests (in all figures RF means rolling friction) the values of the coefficient of resistance to rolling $\overline{f_{r}}$ remain unchanged if $F_{N}=$ const; this agrees with the numerous known data. Depending on the contact stresses, the values of $\overline{f_{r}}$ are
0.0626 at $p_{0}=2000 \mathrm{MPa}$ (elastic contact) as well as 0.0830 at $p_{0}=3200 \mathrm{MPa}$ and 0.0887 at $p_{0}=5600 \mathrm{MPa}$ (elastoplastic contact); i.e., the transition from elastic contact to elastoplastic results in a higher coefficient of resistance to rolling (by $\sim 41.6 \%$ under the test conditions).

(2) During the mechano-rolling fatigue tests (rolling friction + cyclic bending) the values of the coefficient of resistance to rolling $\overline{f_{\sigma}}$ in the compression zone diminish, as a rule. The increase in the bending stresses $\sigma_{a}$ to $640 \mathrm{MPa}$ leads to the reduction of $\overline{f_{\sigma}}$ by $5.1 \%$ at $p_{0}=2000 \mathrm{MPa}$, by $6.0 \%$ at $p_{0}=3200 \mathrm{MPa}$, and by $0.9 \%$ at $p_{0}=5600 \mathrm{MPa}$.

(3) Conversely, during the mechano-rolling fatigue tests with friction occurring in the compression zone, the values of the coefficient of resistance to rolling $\overline{f_{\sigma}}$ grow. The increase in the bending stresses $\sigma_{a}$ to $640 \mathrm{MPa}$ results in the rise of the coefficient $\overline{f_{\sigma}}$ by $11.7 \%$ at $p_{0}=2000 \mathrm{MPa}$, by $5.6 \%$ at $p_{0}=3200 \mathrm{MPa}$, and by $0.13 \%$ at $p_{0}=5600 \mathrm{MPa}$.

(4) The most pronounced effect of the cyclic stresses on the coefficient of resistance to rolling occurs in the elasticity range $\left(p_{0}=2000 \mathrm{MPa}\right)$. In transition to plastic contact, this effect weakens and the effect is weaker the greater the plastic strain.

\section{ANALYSYS OF THE TEST RESULTS}

It is shown in work [5] that the friction process in a force system is characterized by the parameter $f_{F}= \pm \sigma_{a} / \tau_{W}$, which is called the friction index. The following dependence of $\overline{f_{\sigma}}$ on the ratio $\sigma_{a} / \tau_{W}$ is proposed for sliding friction [6]:

$$
f_{\sigma}=f_{S}\left(1 \pm \mu_{p} \frac{\sigma_{a}}{\tau_{W}}\right)=f_{S}\left(1 \pm \mu_{p} f_{F}\right)
$$

where $\mu_{p}$ is the dimensionless parameter of the interaction of the damages caused by the contact and offcontact loads (the frictional and mechanical stresses).

In the case of rolling friction, we replot the dependences presented in Fig. 2 using the parameter $\sigma_{a} / p_{0}$ (Fig. 3). It is easy to see that all of the graphs shown in Fig. 3 can be approximated by the following linear equation of one type

$$
\overline{f_{\sigma}}=\overline{f_{r}} \pm a_{r} \frac{\sigma_{a}}{p_{0}},
$$

where $a_{r}$ is the parameter characterizing the angle of the slope of the straight lines $f_{\sigma}\left( \pm \sigma_{a} / p_{0}\right)$ to the abscissa axis.

Analysis of the experimental data in accordance with equation () is presented in Table 1 . 


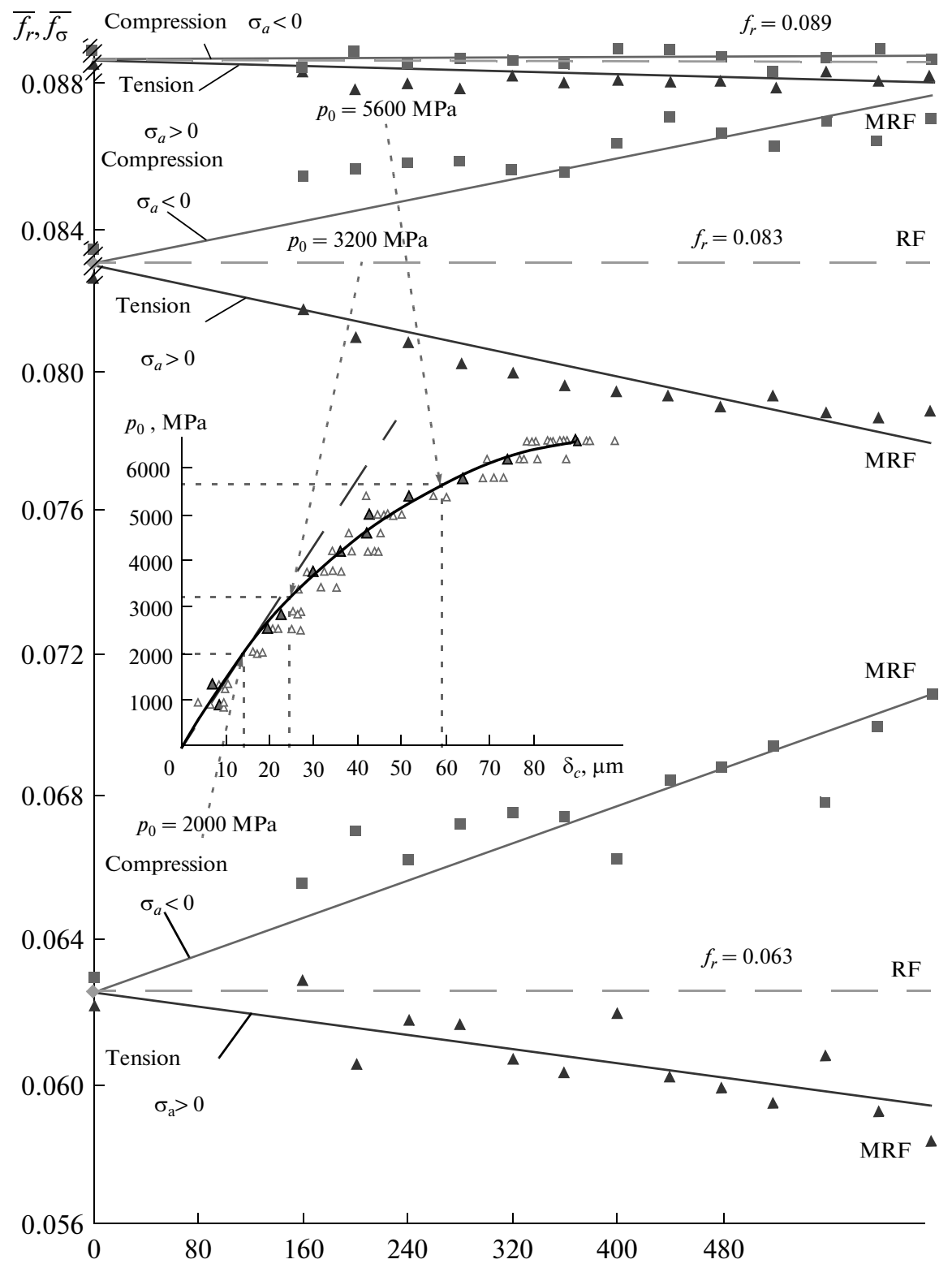

Fig. 2. Force system steel $18 \mathrm{KhGT} /$ steel $18 \mathrm{KhGT}$ : dependence of average coefficient of resistance to rolling $\bar{f}_{r}$ on amplitude of stresses $\sigma_{a}$ (the dashed line corresponds to the value of $\bar{f}_{r}$ in the tribopair).

It is easy to show that equations (4) and (5) are almost identical, since

$$
\begin{aligned}
& f_{\sigma}=f_{r} \pm a_{r} \frac{\sigma_{a}}{p_{0}}=f_{r}\left(1 \pm \frac{a_{r}}{f_{r}} \frac{\sigma_{a}}{p_{0}}\right) \\
& =f_{r}\left(1 \pm \mu_{r} \frac{\sigma_{a}}{p_{0}}\right)=f_{r}\left(1 \pm a_{r} f_{F}\right),
\end{aligned}
$$

where $\mu_{r}=a_{r} / f_{r}$ is the dimensionless parameter of the interaction of the damages caused by the contact and off-contact loads (the frictional and mechanical stresses). By analogy, we can obtain $\mu_{p}=a_{S} / f_{S}$.

The values of the parameter $\mu_{r}$ calculated from the experimental data are given in Table 1.
The methods of the mechanics of deformable solids were applied in work [4] to determine the friction coefficient (the coefficient of resistance to rolling) in the force system:

$$
f=f^{(s)}\left[1 \pm k_{\sigma / p}\left(\frac{\sigma_{y y}^{(b)}}{p_{0}}\right)\right],
$$

where $f^{(s)}$ is the pure rolling friction coefficient and $k_{\sigma / p}$ is the function, which possesses the following values depending on the method of its determination: $k_{\sigma / p}^{(1)}=0.225$ and $k_{\sigma / p}^{(2)}=0.787$.

It is seen that formulae () and (4) are almost identical. 


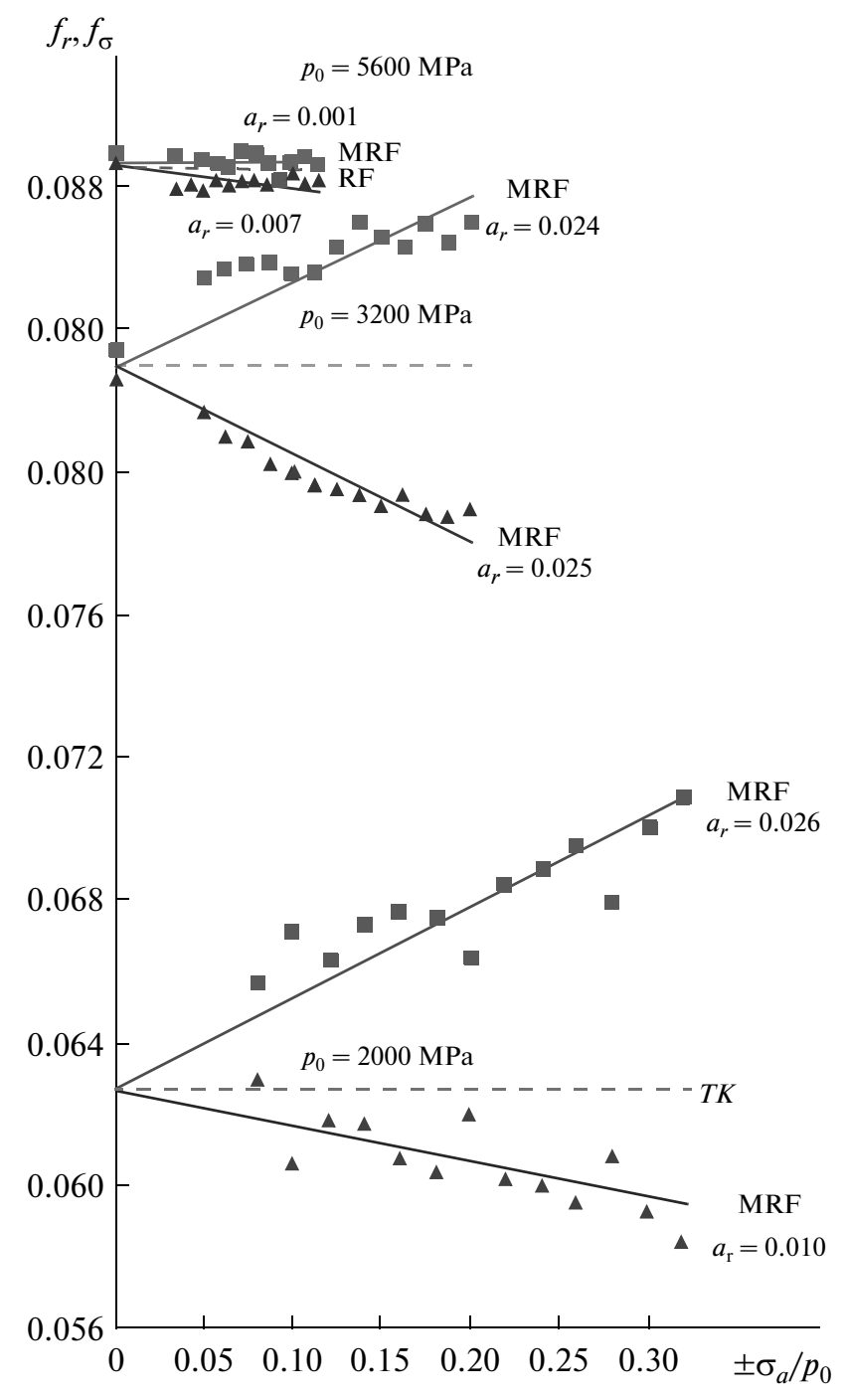

The results of the comparison of the experimental and theoretical values of the coefficient of resistance to rolling in the force system at $k_{\sigma / p}^{(1)}=0.225$ and $\sigma_{a} / p_{0}=$ 0.3 are presented in Table 2.

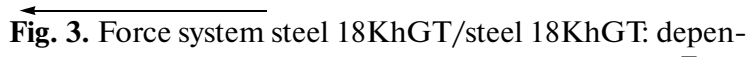
dence of average coefficient of resistance to rolling $\bar{f}_{r}$ on ratio $\sigma_{a} / p_{0}$ (the dashed line corresponds to the value of $\bar{f}_{r}$ in the tribopair).

It can be seen that in this case the calculation estimates agree satisfactorily with the experimental data both qualitatively (the regularities) and quantitatively (the numerical values).

\section{CONCLUSIONS}

The following basic regularities of the effect of the cyclic stresses $\sigma_{a}$ on variations in the coefficient of resistance to rolling $f_{r}$ (the force $F_{R}$ ) are established: (a) greater $\sigma_{a}$, and therefore higher ratio $\sigma_{a} / p_{0}$, entails a more significant variation of the coefficient of resistance to rolling; this regularity is observed in both elastic and elastoplastic contact; (b) the change of the coefficient of resistance to rolling $f_{r}$ with varying cyclic stresses $\sigma_{a}$ reaches $12.5 \%$ in elastic contact and up to $4 \%$ in elastoplastic contact. The cycle stress amplitude in the experiments $\sigma_{a}$ does not exceed the endurance limit $\sigma_{-1}=640 \mathrm{MPa}$ and the ratio $\sigma_{a} / p_{0}$ varies within the $0-0.33$ range.

It is shown that the calculated estimates agree satisfactorily with the experimental data both qualitatively (the regularities) and quantitatively (the numerical values). The error of the experimental and theoretical results of determining the coefficient of resistance to rolling does not exceed $7 \%$.

The presented data are of great practical importance since they open the way to control the friction processes by varying off-contact loads as effectively as by varying contact loads.

Table 1. Analysis of experimental results

\begin{tabular}{|c|c|c|c|c|c|c|}
\hline \multirow{2}{*}{$\begin{array}{l}\text { Maximum } \\
\text { contact pres- } \\
\text { sure } p_{0}, \mathrm{MPa}\end{array}$} & \multirow{2}{*}{ Conditions of friction } & \multicolumn{3}{|c|}{ Parameters } & \multirow{2}{*}{$\begin{array}{c}\text { Equation } \\
f_{\sigma}=f_{r} \pm a_{r}\left(\sigma_{a} / p_{0}\right)\end{array}$} & \multirow{2}{*}{$\begin{array}{c}\text { Range of } \sigma_{a}, \\
\mathrm{MPa}\end{array}$} \\
\hline & & $a_{\mathrm{r}}$ & $\mu_{p}$ & $\mu_{p} / a_{r}$ & & \\
\hline \multicolumn{7}{|c|}{ Force system steel $18 \mathrm{KhGT}\left(\right.$ shaft) $/$ steel $18 \mathrm{KhGT}($ roller $)\left(\sigma_{-1}=640 \mathrm{MPa}, p_{f}=1272 \mathrm{MPa}\right)$} \\
\hline \multirow[t]{2}{*}{2000} & In tension zone & 0.010 & 0.160 & 16.00 & $0.063-0.010\left(\sigma_{a} / p_{0}\right)$ & \multirow{6}{*}{$\sigma_{a} 640$} \\
\hline & In compression zone & 0.026 & 0.415 & 15.96 & $0.063+0.056\left(\sigma_{a} / p_{0}\right)$ & \\
\hline \multirow[t]{2}{*}{3200} & In tension zone & 0.025 & 0.301 & 12.04 & $0.083-0.025\left(\sigma_{a} / p_{0}\right)$ & \\
\hline & In compression zone & 0.024 & 0.289 & 12.04 & $0.083+0.024\left(\sigma_{a} / p_{0}\right)$ & \\
\hline \multirow[t]{2}{*}{5600} & In tension zone & 0.007 & 0.079 & 11.29 & $0.089-0.007\left(\sigma_{a} / p_{0}\right)$ & \\
\hline & In compression zone & 0.001 & 0.011 & 11.00 & $0.089+0.001\left(\sigma_{a} / p_{0}\right)$ & \\
\hline
\end{tabular}


Table 2. Determination of calculation of error of coefficient of resistance to rolling based on experimental results and theoretical states

\begin{tabular}{|c|c|c|c|c|c|c|c|c|c|}
\hline \multirow{3}{*}{ Force system } & \multirow{3}{*}{$p_{0}, \mathrm{MPa}$} & \multirow{2}{*}{\multicolumn{2}{|c|}{$\begin{array}{l}\text { Parameter of interaction, } \\
\qquad a_{r}\end{array}$}} & \multicolumn{4}{|c|}{ Friction coefficient in force system $f_{\sigma}$} & \multirow{2}{*}{\multicolumn{2}{|c|}{ Error, \% }} \\
\hline & & & & \multicolumn{2}{|c|}{ experimental results } & \multicolumn{2}{|c|}{ calculations by (4) } & & \\
\hline & & $\sigma>0$ & $\sigma<0$ & $\sigma>0$ & $\sigma<0$ & $\sigma>0$ & $\sigma<0$ & $\sigma>0$ & $\sigma<0$ \\
\hline \multirow{3}{*}{ Steel 18KhGT/Steel 18KhGT } & 2000 & 0.010 & 0.026 & 0.060 & 0.070 & 0.058 & 0.067 & 2.06 & 5.08 \\
\hline & 3200 & 0.025 & 0.024 & 0.076 & 0.090 & 0.077 & 0.089 & 2.51 & 1.77 \\
\hline & 5600 & 0.007 & 0.001 & 0.087 & 0.089 & 0.083 & 0.095 & 4.49 & 6.39 \\
\hline
\end{tabular}

\section{DESIGNATONS}

$F_{N}$-contact load; $F_{S}$-sliding friction force; $F_{R}$-rolling friction force; $f(p)=f_{r}$-coefficient of resistance to rolling in tribopair; $\tau_{W}$-frictional stress (specific friction force); $p$-contact pressure; $\sigma\left(\sigma_{a}\right)$-cyclic stresses (cycle stress amplitude); $f(p, \sigma)=f_{\sigma}$-coefficient of resistance to rolling in force system; $p_{0}$-maximum contact stress in center of contact zone; $\delta_{c}$-approach of axes (in tribopair); $\mu_{S}$-dimensionless parameter of interaction of damages caused by contact and off-contact load (frictional and mechanical stresses); $f_{F}$-complex indicator of friction in force system (friction index); $a_{r}$ - parameter characterizing angle of slope of straight lines $f_{\sigma}\left( \pm \sigma_{a} / p_{0}\right)$ to abscissa axis; $\mu_{p}$-dimensionless parameter of interaction of damages caused by contact and off-contact load (frictional and mechanical stresses); $f^{(s)}$ - friction coefficient during pure rolling; $k_{\sigma / p}$-function taking into account effect of ratio $\sigma_{y y}^{(b)} / p_{0}$ on friction coefficient variations.

\section{REFERENCES}

1. Frolov, K.V., et al., Sovremennaya tribologiya: Itogi $i$ perspektivy (Contemporary Tribology: Results and Perspectives), Moscow: Mashinostroenie, 2008.

1 2. Myshkin, N.K. and Petrokovets, M.I., Tribologiya. Printsipy I prilozheniya (Tribology. Principles and Applications), Gomel': IMMS NANB, 2002.
3. Osnovy tribologii: Uchebnik (Fundamentals of Tribology: A Textbook), Chichinadze, A.V., Ed., Moscow: Mashinostroenie, 2001.

4. Sosnovskii, L.A., Zhuravkov, M.A., and Shcherbakov, S.S., Fundamental'nye i prikladnye zadachi tribofatiki: kurs lektsii (Fundamental and Application Problems of Tribofatigue: Course of Lectures), Minsk: Belar. Gos. Univ., 2010.

5. Sosnovskii, L.A., Mekhanika iznosoustalostnogo povrezhdeniya (Mechanics of Tribofatigue Damage), Gomel': BelGUT, 2007.

6. Shcherbakov, S.S. and Sosnovskii, L.A., Mekhanika tribofaticheskikh sistem (Mechanics of Tribofatigue Systems), Minsk: Belar. Gos. Univ., 2010.

7. Sosnovskii, L.A., Komissarov, V.V., and Shcherbakov, S.S., Procedure of the Experimental Research of the Friction in Force System, J. Friction Wear, 2012, vol. 33, no. 2, pp. 174-184.

8. Tyurin, S.A., Shcherbakov, S.S., and Sosnovskii, L.A., Comparative Study of Friction Coefficients at Rolling and Contact-Mechanical Fatigue, Zavodskaya Laboratoriya, 2005, vol. 71, no. 2, pp. 48-51.

9. GOST (State Standard), 30755-2001. Tribofatigue. Machines for Wear-Fatigue Testings. General Technical Studies. Intr. 01.07.02., Minsk: Mezhgos. Sovet po Standartizatsii, Metrologii i Sertifikatsii, 2007.

10. GOST (State Standard of Belarus) 1233-2000. Tribofatigue. Tribofatigue. Methods of Wear-Fatigue Testings. Accelerated Testings on Contact-Mechanical Fatigue. Intr. 01.10.07., Minsk: Mezhgos. Sovet po Standartizatsii, Metrologii i Sertifikatsii, 2007.

SPELL: 1. ok 